\title{
Teaching college chemistry in the time of COVID-19 pandemic: A personal account of teaching in the old normal us. the new normal
}

\author{
Armando M. Guidote Jr. ${ }^{1,2 *}$ \\ ${ }^{1}$ Department of Chemistry, School of Science and Engineering, Loyola Schools, Ateneo de Manila University, \\ Katipunan Ave., Loyola Heights, Quezon City, Philippines 1108 \\ ${ }^{2}$ Philippine Institute of Pure and Applied Chemistry (PIPAC), Ateneo de Manila University Campus, Katipunan \\ Ave., Loyola Heights, Quezon City, Philippines 1108
}

*Author to whom correspondence should be addressed; email: aguidote@ateneo.edu

\begin{abstract}
The SARS CoV-2 (Severe Acute Respiratory Syndrome CoronaVirus 2), cause of COVID-19 (CoronaVirus Disease 2019) has afflicted close to 10 million people all over the world resulting to almost half a million deaths. This disease is severely contagious and necessitates social or physical distancing between persons. As such, traditional face-to-face learning is not advised and teachers need to shift to online teaching. There are challenges to online teaching and learning for students, teachers, and the higher education institute, e.g. hardware, bandwidth, and software issues. These will be difficult but these can be overcome eventually. This work is a personal account of the old normal or traditional way of teaching Organic Chemistry and the transition to the new normal of teaching on-line. On-line teaching can be as effective as traditional teaching but everyone has to put in effort and participate in training to get used to this. In the end, it is the teacher's being a true teacher that matters, that the teacher teaches to the best of his or her ability even during this time of the COVID-19 pandemic.
\end{abstract}

Keywords: Chemistry teaching; Organic chemistry; Laboratory Classes; COVID-19

\section{INTRODUCTION}

As of this writing, 23 June 2020, the Philippines logged a record high 1,150 new cases of COVID19 in a single day (Sabillo 2020). Total infections are 31,825 with 8,442 recoveries and 1,186 deaths. Worldwide, 9.1 million people have already been infected based on the Johns Hopkins dashboard (Johns Hopkins Corona Virus Resource Center 2020). 
The SARS CoV-2 (Severe Acute Respiratory Syndrome CoronaVirus 2), cause of the deadly COVID-19 (CoronaVirus Disease 2019), is a savage virus and has wrought havoc throughout the world and will continue to do so in the coming months and perhaps in the next years. No surefire remedy has been found. There is no vaccine yet as of this time.

The effect of COVID-19 differs from person to person. Some will be merely carriers while others; especially those with advanced age or compromised immune status, are more susceptible to it, and even die from it (WHO 2020).

According to the WHO, "the most common symptoms of COVID-19 are fever, dry cough, and tiredness. Other symptoms that are less common and may affect some patients include aches and pains, nasal congestion, headache, conjunctivitis, sore throat, diarrhea, loss of taste or smell or a rash on skin or discoloration of fingers or toes. These symptoms are usually mild and begin gradually. Some people become infected but only have very mild symptoms."

COVID-19 is severely contagious, spreading mostly through contact and droplet transmission (Shereen 2020). Globally, the virus has weighed heavily on most countries' healthcare systems. Hospitals are at risk of getting overwhelmed with limited bed capacity, personal protective equipment and medical equipment should the infection rate continue to rise (Park 2020 and Ranney et al 2020). This is especially true for the Philippines, with hospitals across Metro Manila reaching full capacity and more even with lockdown in place (Ornedo 2020).

Traditional learning based on face-to-face interactions is a dangerous setting for the spread of this disease. Social or physical distancing controls the spread of COVID-19. New modes of teaching based on this are thus necessary so that learning continues. This paper describes my personal account during the shift of the teaching mode in the midst of the pandemic.

I have been teaching college chemistry for approximately twenty-five years. I teach mostly Organic Chemistry (lecture and lab) and sometimes, Analytical Chemistry (lecture and lab). I also teach General Chemistry and Science, Technology \& Society for science and non-science majors as well as Science Education and Chemistry Education to teachers who are graduate students. I have been used and accustomed to the traditional way of classroom-based teaching.

The Old Normal: Lecture Classes. I will describe first the way I teach an Organic Chemistry course in the classroom-based setting pre-COVID19. For lecture, I use the chalk and talk method (or white board marker and talk), Power Point presentations (seldom), demonstrations (seldom, in light of laboratory work), stories (organic chem-related or about life), molecular models, recitation, quizzes, and exams. I ask students to answer all problems within and at the end of the chapter. This is not required but can bring up grades in borderline cases. I make available to them the Study Guide so that they can check their answers or find out the answers and explanations in case they are stumped. In the last decade, I have asked students to download ChemSketch and study it on their own - again not required - but helpful for nice laboratory reports, or practice for naming and stereochemistry. This is of course needed for a career in chemistry. In the past, I also had an optional extra meeting, a problem-solving session, where we answer and discuss the problems in the book. It serves as practice, and with practice, one gets used to answering problems, thinking critically, and being creative. As I got busier, I had a teaching assistant handle this.

I like having an interactive class - I call on students to recite, explain mechanisms or comment on a classmate's answer. This trains them to be on their toes and develop oral communication skills. This gives me feedback on whether to explain further or repeat a lesson. This helps me memorize all my students' names. My goal is to memorize all my students' names by the second or third week 
of classes. I like being able to call everyone and let them know that I know them all by name that all of them are important to me.

I happily tell my classes that I do not give surprise quizzes - because there is, practically, a quiz every meeting at the start of class. These are not meant to terrorize students though some are. They are meant to instill preparedness, to form the habit of studying a little every day, and build composure. My ten-point quizzes vary from identification, structure writing, naming, synthesis, mechanisms, and essay on concepts. I discuss the answers immediately after the quiz. I usually return the quizzes checked the next meeting to give immediate feedback to the students on their learning and performance. I especially like essay questions because it brings to light whether a student really understood a lesson fully, partially, or not at all. This tells me whether I taught well or whether I have to repeat a lesson. As an important skill, the essay questions train the students to improve their written communication given a limited time. A correct but not well-written answer gets only $9 / 10$.

Several times too, I was blessed with team teaching Organic chemistry with a younger faculty member. The team teaching was meant for mentoring of the younger teacher. But $\mathrm{I}$ have learned much from them too. They have brought in online games in class. They explained in a language more suitable to the new generation of students.

The New Normal: Online Classes. During this COVID-19 pandemic season, I cannot do my usual teaching style in lecture classes. Face-to-face learning is very dangerous due to possible transmission of the virus. I have to learn on-line teaching. There are many tools around. But for a relatively old teacher like me, they are not easy to learn. I need more time compared to the young tech-savvy teachers.

Fortunately, my university provides training through the Ateneo SALT - Science and Art of Learning and Teaching - Institute. I can also count on the young faculty members to assist me. I am especially lucky because my wife (from DLSU) has been using on-line teaching for a few months already - I have my personal tutor at home! She does not know everything but she continues to learn and there are also very helpful YouTube videos. One has to jump in and learn this, however, difficult it may be.

With online teaching tools: Google Classroom, Moodle, or Canvas, I can still teach with the use of a presentation to a set of students at real time. I can still have quizzes. I can still ask them to solve all the problems in the book. I can still call on them and make them recite online. I can still make live chemical reaction/phenomenon demonstrations if I want to, or perhaps upload a video of the chemical reaction demonstration/phenomenon - this guarantees no failure. However, doing these online is not straight forward especially for an older person like me.

I have to learn how to set-up my class online. I have to make modules and set-up assignments and quizzes. I have to make sure to have them sent to the correct class. I have to prepare my database of questions for my quizzes and exams. All these take time. But many times, I get lost. I have to repeat many things. I need to Google some of the simple things I want to do like delete a course or draw a molecule. It is difficult, but I am learning. And this is living what we want to teach to students - lifelong learning.

For a senior faculty member, the shift to online teaching is a challenge. But for young teachers, this is generally easy. I caution the young teachers though, but practically all teachers, that we must have our concepts right. We must have breadth and depth. We can be good deliverers of lessons but if these are wrong, we commit a grave disservice. A teacher who effectively conveys a wrong concept is worse than a teacher who ineffectively teaches the correct concepts. We need to have 
the correct chemistry and teach it well. And thus, while we have to learn to teach online, we always have to learn more chemistry by reading books and journals and by doing research. I emphasize the mastery of Content Knowledge especially to my graduate students who are teachers.

On the side of students, there are many challenges to online learning. Some challenges are technical -hardware, bandwidth, and software limitations, and lack of knowledge on the use of both hardware and software. The other challenges will be mostly about character - having the drive to learn independently, discipline, persistence, etc. These traits are needed and hopefully developed whether with traditional or online teaching. These are all easy to write here but we must be sensitive of the mental condition of students. There is the stress of staying put at home, the fear of getting afflicted, the terror of having spread the disease, etc. As a teacher, one has to be aware of all these and know how to empathize.

That is why we cannot talk about the usual semesters anymore. I learned in our Adaptive Design Learning classes by the Ateneo to focus on competency. What in the end is the purpose of the course? Fr. Johnny Go, S.J., our chief trainer, emphasizes not to overwhelm the students especially with the COVID-19 pandemic all over us.

Once the competency is identified, we create modules that will achieve the purpose of the course. The suggestion is to have 4-6 modules per class. Each module will be a combination of synchronous and asynchronous activities. This combination results in fewer students in the whole university simultaneously being engaged in on-line lectures. Too many people accessing the Internet at the same time will result to slow processing and may even result to a system crash.

For the synchronous portion, I plan to discuss online only the most important of concepts that students have difficulty with. Students will be required to have their video ON so that I can see them. These online lectures will have recitation and discussion. For general difficulties, hopefully, email messages will be able to clarify matters. If not, on-line consultation will be necessary.

For the asynchronous portion, I will ask the students to make their own hand written Notes based on the textbook. I found this effective for me when I was a struggling student. The act of writing brings in better understanding. I still use those Notes now from time to time for a quick review. I asked some of my students regarding this and they had a positive feedback on Note taking. I will still require the students to solve problems at the end of the chapter. These must also be handwritten. This will solve the teachers' fear of students copying and pasting answers from their classmates. I was cautioned though that the attachment of the Notes and answers to end of chapters is a challenge to some especially those using prepaid internet load.

These are my plans but the situation varies per teacher, per set of students, and per university. In the end, every teacher will have to decide his or her own way of teaching in the new normal that will answer the challenges faced by their students and the limitations of resources. It is unfortunate though that there will be teachers, students, and higher education institutions who will not be able to adjust quickly to the new normal.

\section{CHALLENGES IN THE LABORATORY CLASSES}

The laboratory classes are a big challenge to teach at this time. The laboratory classes are an effective venue for learning both concepts and skills. I am very fond of the laboratory because this is where Concept Knowledge can be better learned with students experiencing the lessons discussed in class. In Organic Chemistry they experience separation and purification techniques: recrystallization, liquid-liquid extraction, distillation, chromatography, etc. They get to do synthesis and identification of the prepared compounds using qualitative organic chemistry and 
instrumentation chemistry. All these are used in a usual laboratory in industry or the work place and thus have to be mastered.

The laboratory classes teach much other than concepts and skills. In the laboratory, one learns to keep safe for self and for others, to plan, to budget the time, to be patient, compassionate (when one loses one's products), discipline (to use balances properly, to not contaminate reagent bottles, to use limited chemicals, etc.), to cleanup, to work individually, with a partner, or with a group, etc.

In the new normal, it will be very difficult to teach lab the way it was taught in the old normal. Watching a video is very much different from hands-on learning. One learns more by doing.

As a teacher, there is more to teaching all that I have mentioned above. In the laboratory, I get to know students more - their high school background, the reasons for taking up a college course, their interests and hobbies, their friends, their family background, their problems - academic and otherwise, their love life, etc. Of course, not everyone shares everything. I keep this shared information to myself. These are useful to me as a teacher to effectively teach, and teach not just chemistry but teach more than chemistry. In the old normal laboratory setting, there is the faceto-face meeting and that builds trust. I only get to know my students more because they trust me. They share personal information because of trust. In the new normal of on-line teaching, I cannot do this.

For laboratory classes, we have decided in our university to not have laboratory courses this first semester (August to December 2020). We are moving all laboratory classes to the second semester (January to May 2021). Hopefully, there will be a vaccine at that time and we start to move back to the old normal.

\section{OUTLOOK FOR TEACHING IN THE NEW NORMAL}

Assuming that hardware, bandwidth, and software familiarity issues are addressed, maybe there are good things that can come out of this and make the later future hopeful. There will be less travels - good for saving on fuel, lighter traffic for others, and less greenhouse gas emissions. There can be more time being with family. There can be better and more meaningful relationships. In general, there can be less tuition fee expenses because students learn from home. There will be fewer learning disruptions from typhoons and calamities unless electricity and the internet are cut.

Given the situation, I have to accept the changes. In the new normal, I cannot be the same teacher I was before. Certain parts in my teaching philosophy cannot be done without a face-to-face encounter with students. However, there are available technologies that can be used to still conduct effective teaching of concepts and even life skills. It will be different but, in the end, I am a teacher and I will teach to the best of my ability given the constraints this COVID-19 pandemic has bestowed upon us. Surely, there are lessons here that will make everyone a better person, for self, and for others.

In the meantime, I will continue the training in the Adaptive Design Learning Course. Tomorrow we have a double feature: "Projecting Your Teacher Persona: Prepping to Teach on Cam" by Ms. Missy Maramara of the AdMU Fine Arts Department, and "Teaching from a Different Box: More of the Same with a Twist" by Mr. Sev Sarmenta of the AdMU Communications Department. Indeed, learning continues. 


\section{REFERENCES}

Johns Hopkins Corona Virus Resource Center. COVID-19 Dashboard by the Center for Systems Science and Engineering (CSSE) at Johns Hopkins University (JHU). https://coronavirus.jhu.edu/map.html Last accessed 23 June 2020

Ornedo, J.M. Philippines' healthcare overwhelmed if COVID-19 cases not controlled, UP experts say. GMA News, April 22, 2020.

https://www.gmanetwork.com/news/scitech/science/735023/up-experts-predictoverwhelmed-healthcare-system-urge-officials-to-flatten-covid-19-curve-soon/story/ last accessed 23 June 2020.

Park C.-Y., Kim K., Roth S., Beck S., Kang J.W., Tayag M.C., Griffin M. Global Shortage of Personal Protective Equipment amid COVID-19: Supply Chains, Bottlenecks, and Policy Implication. Asian Development Bank (ADB), April 2020.

Ranney M.L., Griffeth V., Jha A.K. Critical Supply Shortages - The Need for Ventilators and Personal Protective Equipment during the Covid-19 Pandemic. The New England Journal of Medicine 2020; 382:e41.

Sabillo K. Philippines logs record-high 1,1,50 new COVID-19 cases in a single day; raise total to 31,825. ABS-CBN News. https://news.abs-cbn.com/news/06/23/20/philippines-logs-recordhigh-1150-new-covid-19-cases-in-a-single-day-raises-total-to-31825 Last accessed 23 June 2020.

Shereen M.A., Khan S., Kazmi A., Bashir N., Siddique R. COVID-19 infection: Origin, transmission, and characteristics of human coronaviruses. Journal of Advanced Research 24(2020) pp. 91-98.

WHO Q\&A on coronaviruses (COVID-19) https://www.who.int/emergencies/diseases/novelcoronavirus-2019/question-and-answers-hub/q-a-detail/q-a-coronaviruses Last accessed 23 June 2020 . 